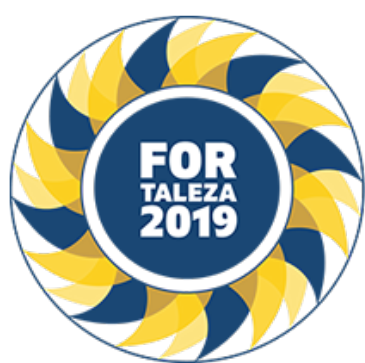

\title{
CHRONIC ANKLE MONOARTHRITIS DUE TO TUBERCULOSIS IN AN IMMUNOCOMPETENT INDIVIDUAL
}

Rodrigo Barbosa de Azevedo (hospital geral dr cesar cals, fortaleza, CE, Brasil), João Tarcisio Alves Maia Filho (hospital geral dr cesar cals, fortaleza, CE, Brasil), Isadora Sucupira Machado (hospital geral dr cesar cals, fortaleza, CE, Brasil), Silviane Praciano Bandeira (hospital geral dr cesar cals, fortaleza, $C E$, Brasil), Thalita do Nascimento Silva (hospital geral dr cesar cals, fortaleza, CE, Brasil), Nícolas Breno Gomes de Lima (hospital geral dr cesar cals, fortaleza, CE, Brasil), Sarah Barreira Cavalcante (Hospital Haroldo Juaçaba, fortaleza, CE, Brasil), Priscila Dourado Evangelista (hospital geral dr cesar cals, fortaleza, CE, Brasil)

\section{BACKGROUND}

Tuberculosis (TB) is an infectious disease, transmitted almost exclusively by cough aerosol, caused by the Mycobacterium tuberculosis complex, and characterised pathologically by necrotising granulomatous inflammation usually in the lung, although almost any extrapulmonary site can be involved. About 1-3\% of all cases of TB involve bones and joints and only $10 \%$ of osteoarticular TB affects the foot and ankle. The diagnosis of TB arthritis is often overlooked because of the insidious onset and the non-specific clinical symptoms, leading to a high grade of morbidity due tue degenerative changes of the articular cartilage and the bone.

\section{CASE REPORT}

R.P.S, 67 years old, male, 2 years ago presents a nodular lesion on the right foot, evolving with edema and pain in the right ankle, limiting the moviments. Physical examination shows painful edema on the dorsum of the right foot and ankle, without heat or local hyperemia. MRI of the right foot (Figure 1 and 2) shows edematous infiltrative process in navicular bones, cuneiformes, distal fibula, base of the 2nd metatarsal and in mild degree in the upper calcaneal and posterior portion of the talus, with marked circumjacent synovitis. A joint puncture was performed with purulent liquid drainage (Figure 3), being isolated Mycobacterium tuberculosis in the study of synovial liquid (Figure 4). Started daily treatment with rifampicin and isoniazid, associated with pyrazinamide and ethambutol in the first 2 months, followed by 10 months of use of rifampicin and isoniazid. After 1 year of treatment, patient evolves with complete improvement of edema and joint symptoms, without sequelae or need for surgical procedures.

\section{CONCLUSION}

Tuberculous arthritis of the ankle has high morbidity but often goes undiagnosed, and can lead to degenerative changes in the bone and articular cartilage and even to joint collapse.Timely diagnosis and correct treatment are important to avoid functional disability. 